\title{
Relectura de La muerte de La Quimera. Tragicomedia en dos actos, para marionetas. Emilia Pardo Bazán, el teatro de marionetas y el «teatro de ensueño»
}

\section{Rereading of La muerte de La Quimera. Tragicomedia en dos actos, para marionetas. Emilia Pardo Bazán, the Puppet Theater and the «Teatro de Ensueño»}

\author{
Patricia Carballal Miñán \\ Universidade da Coruña \\ patricia.carballal@udc.es \\ ORCID iD: https://orcid.org/0000-0001-9360-5663
}

\section{RESUMEN}

La muerte de la Quimera. Tragicomedia en dos actos, para marionetas es una breve pieza dramática de Emilia Pardo Bazán que — como damos noticia por vez primera en este artículonació para ser representada en un teatro de marionetas proyectado por el escritor modernista Antonio de Hoyos y Vinent en 1903. Sin embargo, la suspensión del proyecto escénico por razones que desconocemos y la decisión de Emilia Pardo Bazán de situar La muerte de la Quimera al frente de su novela de 1905 La Quimera, parecen haber llevado a la crítica a estudiar este texto como un mero proemio a la narración protagonizada por Silvio Lago. El siguiente estudio, sin embargo, propone recatalogar la breve tragicomedia dentro del teatro de ensueño modernista y del teatro para títeres, espectáculos llamados a renovar el anquilosado panorama teatral de entre siglos en el que se sitúa toda la obra dramática de la escritora.

Palabras Clave: Emilia Pardo Bazán; La muerte de la Quimera. Tragicomedia en dos actos, para marionetas; teatro de marionetas; teatro de ensueño; renovación teatral.

\section{ABSTRACT}

La muerte de la Quimera. Tragicomedia en dos actos, para marionetas is an Emilia Pardo Bazán's short piece of drama —as we inform for the first time in this article - that was born to be represented at a puppet theater designed by the modernist writer Antonio de Hoyos y Vinent in 1903. However, the suspension of La muerte de la Quimera in front of his 1905 novel La Quimera, have led critics to study this text as a mere preface to narration starring by Silvio Lago. Nevertheless, the next study suggests to catalog the brief tragicomedy inside the modernist «teatro 
de ensueño» and of the theater to puppet, shows were called to renew the stagnant theater scene from centuries in which lies the whole drama of the writer.

Key words: Emilia Pardo Bazán; La muerte de la Quimera. Tragicomedia en dos actos, para marionetas; Puppet theater; «teatro de ensueño»; Theater renovation.

\section{INTRODUCCIÓN}

La muerte de la Quimera. Tragicomedia en dos actos, para marionetas, es un pequeño texto teatral de Emilia Pardo Bazán que por una decisión meramente editorial de la escritora sirvió como proemio a su novela La Quimera publicada en 1905. No obstante, la publicación conjunta de los dos textos provocó que hasta ahora esta breve pieza dramática solamente se haya leído en relación a la citada novela y que no se haya atendido ni a sus propias peculiaridades ni a su finalidad escénica.

Sin embargo, un análisis minucioso nos ha desvelado que La muerte de la Quimera fue un texto escrito para ser representado con marionetas en un teatro particular y que, además, supuso un importante eslabón en el proceso de renovación teatral en el que se inmiscuyó Emilia Pardo Bazán desde las postrimerías del siglo XIX. Así, lejos de ser leída meramente como un pretexto, La muerte de la Quimera. Tragicomedia en dos actos, para marionetas es una pieza que se inscribe dentro del teatro de ensueño de raíces maeterlinckianas y que pertenece al corpus hispano del teatro de títeres ${ }^{1}$, «una de las modalidades más cultivadas por los autores más radicalmente renovadores del primer tercio del siglo XX» (Gómez Torres 1994). Pensamos que un estudio detenido de esta breve pieza podría contribuir a reubicar la obra teatral de Emilia Pardo Bazán como una de las principales tentativas de la regeneración escénica española de principios del siglo $\mathrm{XX}^{2}$.

\section{LA RENOVACIÓN DEL TEATRO DECIMONÓNICO}

A finales del siglo XIX surgieron por toda Europa una serie de intelectuales que pusieron en solfa la dramaturgia vigente. En el plano espectacular, denun-

${ }^{1}$ Siguiendo a Ayuso y Millán (2001:7) a lo largo de este trabajo utilizaremos indistintamente las voces «marionetas» y «títeres» para referirnos a los muñecos usados en las representaciones teatrales y movidos por cualquier técnica.

2 Se ha analizado desde esta perspectiva toda la dramaturgia pardobazaniana en la tesis doctoral Carballal Miñán, Patricia (2015). El teatro de Emilia Pardo Bazán. Datos para a su historia escénica y para su recepción crítica. Tesis doctoral. A Coruña: Universidade da Coruña. 
ciaron el interés comercial de los teatros que, descuidaban las puestas en escena y que, muchas veces, eran tomados por compañías de actores y actrices de interpretación excesivamente afectada, a quienes los autores parecían rendirse. En el plano literario — recordemos la condición dupla de la dramaturgia ${ }^{3}$ - , acusaron la distancia del teatro con respecto a otros géneros literarios que habían filtrado vientos de cambio a la literatura decimonónica. Así, y como respuesta a esta situación surgieron corrientes como la defendida por Zola en Francia que hundía sus raíces en la tradición realista de la novela $-\mathrm{y}$ que tendría concomitancias con autores como Benito Pérez Galdós que pugnaban por un mayor verismo en la ejecución de las obras - o como las que, en dirección contraria, se aproximaban a la idealidad de la escena «para escapar de las limitaciones materiales del espectáculo» (Rubio 1993: 104) siguiendo las directrices del simbolismo poético, que influirían a Jacinto Benavente, a Gregorio Martínez Sierra ${ }^{4}$ y a María de la O Lejárraga o a Ramón del Valle-Inclán.

Preocupada también por la regeneración dramática española, Pardo Bazán cultivó el teatro desde muy joven ${ }^{5}$ y, bajo nuestro punto de vista, gestó toda una carrera que proponía una renovación del género. Y si bien su proyecto dramático hundió sus raíces en el realismo de la novela y sus textos sobre la dramaturgia pugnaron por la verosimilitud de la escena y la naturalidad de los intérpretes, también su obra teatral acusó la recepción del teatro simbolista que tendría como referente al escritor belga Maurice Maeterlinck, en cuyas propuestas más radicales defendía sustituir la corporeidad material de los actores y actrices por simples marionetas. La influencia de las corrientes simbolistas y la dramaturgia del escritor belga darían pie, en España, a un género dramático

${ }^{3}$ Esta postura, propuesta por la especialista en semiótica Carmen Bobes (1991: 12), coincide además, distinguiendo en el texto dramático «dos aspectos (...): el Texto Literario y el Texto Espectacular»

${ }^{4}$ A propósito de ese autor, debiéramos indicar que, a tenor de varias investigaciones, parece ser que la mayor parte de su producción fue escrita por su esposa, María de O Lejárraga, tal y como atestiguan, por ejemplo, especialistas como María Isabel López Martínez en su estudio de 2006 «María de la O Lejárraga: la voz suplantada», publicado en Teatro y mujer en España. De los años 20 a la posguerra, Margherita Bernard (ed.), 19-33. Bérgamo: Bérgamo University Press - Sestante Edizioni.

${ }_{5}^{5}$ De ello dan muestra los dramas incompletos El Mariscal Pedro Pardo, Tempestad de invierno, Ángela, la traducción incompleta del drama de Scribe y Legouvé Adriana Lecovreur y el resumen argumental de Plan de un drama que se conservan en el fondo que atesora los documentos de Emilia Pardo Bazán en el archivo de la Real Academia Galega. Por otra parte, en la Fundación Lázaro Galdiano se custodia completa la pieza dramática Perder y salir ganando, editada por vez primera en Carballal Miñán, Patricia (2015). El teatro de Emilia Pardo Bazán. Datos para a su historia escénica y para su recepción críti$c a$. Tesis doctoral. A Coruña: Universidade da Coruña y que puede consultarse en el siguiente enlace: http://hdl.handle.net/2183/14689. Al respecto, véase también la edición de esa pieza, con estudio introductorio y notas, de Dolores Thion Soriano-Mollá en Pardo Bazán (2016). 
cultivado en mayor medida por los escritores próximos al modernismo que daría en llamarse «teatro de ensueño» (Rubio 1993), en cuyo corpus aparecen obras destinadas al teatro de títeres ${ }^{6}$. Precisamente, en este género se inscribe la pieza de la escritora titulada La muerte de la Quimera. Tragicomedia en dos actos, para marionetas, obra que, debido a su suerte editorial — fue publicada en 1905 en el número XXIX de las obras completas de la escritora como proemio a su novela La Quimera ${ }^{7}$, como ya hemos referido- solamente ha sido estudiada en concomitancia con esta ${ }^{8}$.

\section{LA MUERTE DE LA QUimeRA. TRAGICOMEDIA EN DOS ACTOS, PARA MARIONETAS, AL MARGEN DE LA NOVEla LA QUimera}

No es nuestro propósito, por supuesto, rechazar las evidentes relaciones entre la pieza de teatro breve para marionetas y la novela. Simplemente creemos

${ }^{6}$ Una de las tareas pendientes tanto de la historia de la dramaturgia hispana como de la historia escénica es, por ende, clasificar de aquellas obras que fueron destinadas para el teatro de títeres, cuáles fueron finalmente representadas y cómo, y cuáles fueron simplemente editadas y leídas. Sin duda, el teatro de muñecos ha sido insuficientemente estudiado tanto por su carácter popular como, en su variante más renovadora, por la dificultad de trazar un panorama escénico muchas veces relegado a colectivos artísticos privados. Aún así, existen varios trabajos de investigación que se ocupan del tema, como el fundacional estudio de Varey (1956) y los de Vázquez de Castro (2001), Ayuso y Millán (2001) y Pedrosa (2014). También, la crítica valleinclaniana se ha acercado al panorama de los espectáculos de títeres en Lavaud y Lavaud (1992), Villarmea Álvarez (2006) y Espejo Trenas (2012), al tiempo que los estudiosos de García Lorca se han aproximado al tema (Gómez Torres 1994).

7 Pardo Bazán, Emilia (1906). La Quimera. Novela. Madrid: Est. Tip. de Idamor Moreno.

${ }^{8}$ Sin ánimo de ser exhaustivos señalaremos cómo, por ejemplo, Cristina Patiño afirma que «desde el inicio, la Sinfonía. La muerte de la Quimera, se percibe la carga simbólica de la novela, la confrontación que cristalizará en simbiosis, entre la religión y el arte» (Patiño Eirín 1994-1995: 34), o cómo los profesores Darío Villanueva y J. M. González Herrán, en la «Introducción» al tomo V de las Obras Completas de la escritora publicadas por la Biblioteca Castro, hablando de la novela La Quimera afirman que «[i]ndependientemente de su fundamento autobiográfico y de otras claves que no es difícil descifrar (...) el propio simbolismo del título acredita la ambición de la autora de La Quimera al escribirla. El mito helénico del monstruo que vomitaba fuego al que Belerofonte, jinete del alado Pegaso, mata introduciendo en su garganta una pieza de plomo, le sirve a nuestra escritora para representar la aspiración a la idealidad, consustancial a todo proyecto artístico» (Pardo Bazán 1999: XIII). También en su monografía La Quimera de Pardo Bazán y la novela finisecular Daniel S. Whitaker apunta que «La Quimera, y en menor grado la Esfinge, son los motivos centrales de La quimera. La Quimera - el monstruo griego que era, como hemos visto, león por delante, cabra en medio y serpiente por detrás - era la bestia simbólica que, en el siglo XIX, inspiraba a los hombres sueños imposibles. La Quimera es la marioneta de Doña Emilia en la alegoría al comienzo del libro; por ejemplo, provocaba "aspiraciones insanas" a todas las personas vivientes (...). La Quimera es la principal fuerza motriz para Silvio» (Whitaker 1988: 45). 
que esta breve pieza dramática tiene entidad suficiente para ser estudiada al margen de la narración sobre Silvio Lago — trasunto del pintor Joaquín Vaamonde- - Así, si bien, desde el estudio fundacional de Nelly Clemessy de 1973, toda la crítica pardobazaniana está de acuerdo en que La Quimera inaugura «la dernière manère» en la narrativa de la condesa (Pardo Bazán 1999: I), creemos que para analizar correctamente La muerte de la Quimera. Tragicomedia en dos actos, para marionetas debemos estudiarla en relación con los vientos de cambio del teatro de la época.

Pensamos que, tal vez, una de las razones por las que el estudio de este breve texto como obra teatral no ha existido —además del escaso estudio que ha recibido, por ende, el teatro de Pardo Bazán — pudiera ser, como ya hemos referido, la insuficiente atención que se le ha prestado a la historia textual de la novela y de la tragicomedia ${ }^{9}$. A este respecto, los profesores Villanueva y González Herrán, editores de las obras completas de la escritora en la Biblioteca Castro - que tiene como norma que los estudiosos se atengan siempre a la primera edición de los textos-, y que consideraron que la publicación princeps de la novela y la tragicomedia era la publicada por la escritora en sus Obras Completas, declaran que:

Doña Emilia comenzó publicándola [La Quimera] por entregas en la revista $L a$ Lectura desde mediados de 1903 hasta finales de 1905. Ese mismo año, en torno al mes de junio según dan a entender las fechas de sus primeras recensiones, entre ellas la de Luis Morote en El Heraldo, La Quimera aparece en libro como el tomo XXIX de sus Obras Completas, editado en dos volúmenes, sin datar en Madrid (Administración, calle San Bernardo, 37, principal/ Establecimiento tipográfico de Idamor Moreno, Blasco de Garay, 9/, 578 páginas).

La suerte editorial de la novela se complica si tenemos en cuenta la publicación de su prólogo el 21 de septiembre en La Época, periódico que luego reproducirá, con interrupciones e intermitencias, entre 1905 y 1907, el texto de la novela, incluida la «tragicomedia en dos actos para marionetas» (las comillas no son nuestras) La muerte de la Quimera (Pardo Bazán 1999: XXI).

Sin embargo, nuestras investigaciones nos han desvelado nuevos datos y han puntualizado otros ya conocidos. Por un lado, queremos destacar que el tomo de las Obras Completas de la escritora que incluye la novela protagonizada por Minia Dumbría fue publicado hacia mediados de abril de 1905 y no en junio, si tenemos en cuenta uno de los sueltos de la prensa que así lo anunció ${ }^{10}$. La

9 En una nota al Apéndice de su monografía sobre la novela de Pardo Bazán, Whitaker señala que: «En este trabajo no analizaremos el prólogo ni la obra de marionetas, sino que nos dedicaremos exclusivamente a estudiar las revisiones llevadas a cabo por Emilia Pardo Bazán en el texto principal de la novela» (Whitaker 1988: 118, nota 4).

${ }^{10}$ En La Época el 15/04/1905 se publicó un suelto titulado «La Quimera. Nueva novela de la señora Pardo Bazán» en el que se afirma: «Se ha puesto a la venta un nuevo libro 
novela, ciertamente, se había editado en La Lectura desde 1903 sin el prólogo, que fue publicado por la escritora el 21/09/1903 en el diario madrileño La Época. Por tanto, cuando Pardo Bazán realizó la edición de La Quimera en libro en abril de 1905 incluyó el texto de la novela y el prólogo, pero también un nuevo paratexto, como indican Villanueva y González Herrán: «la escritora incorporó como preámbulo al primer capítulo de la narración propiamente dicha una tragicomedia en dos actos para marionetas titulada "La muerte de la Quimera" que le había sido encargada» (Pardo Bazán 1999: XIII).

Efectivamente la breve pieza teatral pasó a formar parte del volumen que vio la luz en abril, pero fue también editada nuevamente muy pocas semanas después, concretamente el 9 de mayo de 1905 en La Época, seguramente como estrategia publicitaria para anunciar la novela de Doña Emilia. Y en un párrafo del diario madrileño que precede a la edición de La muerte de la Quimera. Tragicomedia en dos actos, para marionetas se indican datos muy importantes para su análisis:

Proyectose, hace más de un año, organizar una serie de representaciones de marionetas en casa de un aristócrata escritor.

Con destino a ser representada entonces, escribió la ilustre $\mathrm{D}^{\mathrm{a}}$. Emilia Pardo Bazán una tragicomedia de ensueño, en dos actos, titulada LA MUERTE DE LA QUIMERA. Cuantos la oyeron leer, en aquella ocasión, celebraron la belleza y originalidad de la producción.

El proyecto de representaciones con marionetas no se realizó, y el trabajo de la señora Pardo Bazán quedó inédito, sin tener ocasión de ser aplaudido.

Hoy lo publica, a modo de «sinfonía», en su admirable novela LA QUIMERA, y para que el público saboree sus encantos singulares, lo reproducimos a continuación (Pardo Bazán 1905).

En primer lugar, este texto ratifica la distinta génesis de la novela y de la pieza dramática, solamente unidas por una decisión editorial de su autora. $L a$ muerte de Quimera, como ya hemos referido, no nació como pretexto de la novela citada sino como texto autónomo con una finalidad concreta: para ser representado en un teatrillo de marionetas en el año 1904, lo que vincula a Emilia Pardo Bazán con la práctica del teatro particular, esta vez de títeres, que

de la ilustre escritora $D^{\mathrm{a}}$. Emilia Pardo Bazán, que lleva por título La Quimera y corresponde al tomo XXIX de sus Obras Completas. Es una novela que pinta costumbres de la aristocracia madrileña, y despertará seguramente la curiosidad por el medio social que la pinta, porque del arte con el que está escrita no es necesario hablar; pues basta con consignar el nombre de la escritora para garantir las excelencias de La Quimera. El público que gusta de las buenas producciones literarias ha seguido con interés la publicación de esta novela en las páginas de la revista La Lectura, y ahora que se publica en tomo, seguramente sabrá saborear los múltiples encantos de creación, vida y de amenidad que encierra» («La Quimera. Nueva novela de la señora Pardo Bazán»). Whitaker, en su monografía apunta también erróneamente: «[e]n el otoño de 1905, la novela apareció como el volumen 29 de las Obras Completas de Pardo Bazán» (Whitaker 1988: 118). 
comenzaba a penetrar en los ambientes intelectuales madrileños con el cambio de siglo. En segundo lugar, el texto de La Época incide en calificar la breve pieza como «teatro de ensueño», denominación bajo la cual la crítica de principios de siglo dio en llamar a la corriente teatral deudora del paradigma del simbolismo. En este sentido, tanto el «teatro de ensueño» como el teatro de marionetas nos remiten a ver esta pieza a la luz de la influencia del dramaturgo belga Maurice Maeterlinck.

El estudioso Íñigo Sánchez Llama, que ha analizado la novela La Quimera con exhaustividad, señala:

De la extensísima bibliografía referida a las fuentes estéticas de La Quimera, pueden destacarse los estudios que analizan los vínculos de esta novela con el impresionismo (Giles) y la novelística francesa del XIX en sus distintas variantes: Flaubert (Correa Calderón), los hermanos Goncourt (González Arias) y Émile Zola (Brown, Sotelo Vázquez), (...) la literatura rusa (Bradford, Portnoff), el misticismo franciscano (Clemessy, Wood), el prerrafaelismo (Glascock, Whitacker), el irracionalismo nihilista (Sobejano 182-86), el modernismo (Baquero Goyanes, Varela Jácome), el decadentismo (Kronik) y, en un sentido más amplio, la estética finisecular (Latorre Ceresuela)» (Sánchez Llama 2005: 457).

Sin embargo, ningún crítico se ha detenido a examinar únicamente $L a$ muerte de la quimera al margen de la novela ni ha señalado las influencias literarias que subyacen a su génesis y concepción. No obstante, una lectura atenta de esta breve pieza — escrita entre las postrimerías de 1903 y principios de 1904 — y del diálogo teatral La suerte — estrenado el 5 de marzo de 1904 desvelan parecidos temas como el peso del destino y la fatalidad humana (incluso hasta el punto de que podríamos apuntar que conforman un pequeño ciclo en la dramaturgia de la escritora) y remiten a la influencia de la lectura de las obras de Maurice Maeterlinck por parte de Doña Emilia' ${ }^{11}$.

${ }_{11}$ Al margen de las dos crónicas de «La Vida Contemporánea» —una del 11/01/1904 y otra del 21/03/1904 — que citaremos en las siguientes páginas y en las que la escritora se refirió a Maurice Maetterlinck, Pardo Bazán profundizó en la obra del autor de Pelléas et Melisande en una conferencia que pronunció en la Escuela Superior de Magisterio el 29 de diciembre de 1916 (recogida el 30/12/1916 en El Liberal bajo el título «En la Escuela Superior de Magisterio. Conferencia de la Condesa de Pardo Bazán») y en uno de los capítulos diseñados para formar parte de La Literatura Francesa Moderna: La Decadencia (los originales de ambos textos se conservan en el Archivo de la Real Academia Galega). En el capítulo referido la escritora escribía: «hay otros dramas en que la nota trágica procede de aquel que Segismundo llamó delito mayor del hombre, o sea el haber nacido; en que el hombre sufre por eso, porque vino al mundo, y el mundo en su esencia es dolor y misterio, y, dentro de él, el hombre se siente solo y abandonado y entregado sin defensa a la fatalidad, como los pobres ciegos en la oscuridad. Es esa inmensa pesadumbre del destino general, y no el conflicto de un suceso particular, lo que con felicísima inspiración hace percibir Maeterlinck en los tres poemas que yo tengo por más bellos, profundos y simbólicos, dentro de su obra [L'Intruse, Les Aveugles e Intérieur]». 


\section{Maurice Maeterlinck y el teatro Simbolista}

Como atestigua el profesor Jesús Rubio, la dramaturgia de este escritor había hundido sus raíces en las propuestas de Alfred de Musset o Theóphile Gautier quienes optaban por crear un teatro ideal, que deseaba «escapar a las limitaciones materiales del espectáculo» (Rubio Jiménez 1993: 104) y que serían seguidas por los escritores simbolistas. Desde Francia, Stéphane Mallarmé había formulado "las condiciones de existencia de un "drama futuro" alejado de toda materialidad» (González Salvador 2000: 44) y, en sus textos sobre teatro, el dramaturgo Maurice Maeterlinck promulgaba:

La escena es el lugar en el que mueren las obras maestras, porque la representación de una obra maestra con ayuda de elementos accidentales y humanos es antinómica. Toda obra maestra es un símbolo y el símbolo no soporta nunca la presencia activa de un hombre (González Salvador 2000: 45).

En este sentido, Maeterlinck había concebido una serie de dramas entre 1890 y 1896 que serían conocidos como «dramas para marionetas» (L'Intruse, Les Aveugles, Les Sept Princesses, Pelléas et Mélisande, Alladine et Palomides, Intérieur e La mort de Tintagiles). Sobre ellos el intelectual catalán José Yxart (1894) - uno de los primeros en reflexionar sobre la dramaturgia del escritor belga en la Península Ibérica- comentaría:

Maeterlinck acabó por declarar que el teatro simbólico —el templo del ensueño, tal como lo concibe - no soporta «la presencia activa del hombre en la escena»; y más todavía que «la ausencia del hombre le parecía indispensable». Por aquí se llega lógicamente y en definitiva a las figuras alegóricas y fantásticas, a los títeres o marionnettes (Yxart 1984).

Esta concepción subyacía a toda la propuesta teatral del dramaturgo belga con la que trataba de representar:

El moment en què «l'home és sorprès pel seu destí», lliurat als designis impenetrables de les misterioses potències que, des de les alçades, governen els fràgils fils de la seva existència. Sacsejats per les forces que els transcendeixen, els personatges hi ofereixen un aspecte característic i titellesc — somnambules un peu sourds constamment arrachés à un songe pénible - i situen el lector en un terreny ambivalent on el real i l'ideal, el natural i el sobrenatural, conviuen estretament enllaçats (Carbonell Graells 2004: 9).

Según los críticos de la obra de Maeterlinck, esta concepción surgiría de la confluencia con las ideas de Schopenhauer, quien «compara[ba] el "espectáculo de la raza humana" a una función de marionetas impulsadas no tanto por hilos invisibles como por un "mecanismo interior" infatigable y ciego "que mantiene a los individuos en escena”» (González Salvador 2000: 53). 
INFLUENCIA DEL TEATRO SIMBOLISTA Y DE LA DRAMATURGIA MAETERLINCKIANA EN LA PENÍnsula IBÉRICA

La concepción teatral de Maurice Maeterlinck, como atestigua Jesús Rubio «radicaba en unir las reacciones de los personajes, su drama interior, a los fenómenos naturales exteriores». Además, su propuesta:

Suprimía el decorado descriptivo (...) y renunciaba a cualquier análisis psicológico sistemático, sustituyéndolo por una sugerencia continuamente cambiante. Buscaba transmitir la interdependencia existente entre los fenómenos físicos y los espirituales. Voces y silencio, estatismo y movimiento, se combinaban de manera extraña. Sus personajes trataban de penetrar el misterio de la realidad, de percibir sus voces más profundas (recuérdese Baudelaire), una realidad enigmática y angustiosa fuerza de ser hermética. El fatalismo maeterlinckiano impresionó a los simbolistas y generó toda una literatura derivada de sus cánones (Rubio 1993:106).

En el Estado Español, la influencia de la obra teatral del escritor belga influiría poderosamente en el que daría en llamarse «teatro de ensueño», que impregnando primero a los escritores modernistas, tendría su eclosión entre 1890 y 1910. En esta dramaturgia, autores como Jacinto Benavente, Pérez de Ayala, Valle-Inclán o Gregorio Martínez Sierra y María de la O Lejárraga, en la literatura española y por Santiago Rusiñol o Adriá Gual, en la catalana (Rubio Jiménez 1993: 107 y Carbonell Graells 2004: 44-69) se alejaron del realismo escénico y buscaron la idealidad dramática. Pero su deseo eclosionaba contra los dictados del teatro burgués, interesado en otro tipo de espectáculo. Los espacios de representación y la misma puesta en escena se convirtieron en un problema que ya estaba en la raíz de la propuesta simbolista. No es por ello extraño, que varios de los dramaturgos que se aproximaron al «teatro de ensueño» formaran parte de propuestas ajenas al teatro comercial ${ }^{12}$ y que muchas de sus obras se destinasen al «teatro para la lectura» (Rubio Jiménez 1993: 110).

\section{EL RESURGIR DEL TEATRO DE MARIONETAS EN LA ÉPOCA DE LA RENOVACIÓN ESCÉNICA}

En el «teatro de ensueño», como ocurría con el teatro maeterlinckiano, los personajes se aproximaban a la idealidad y huían del plano corpóreo. Por ello,

\footnotetext{
12 Así, Benavente pone en marcha en 1899 el Teatro Artístico —en que el Valle-Inclán estrenaría una traducción de L'intruse de Maeterlinck- (Anónimo 01/01/1899). Años después, en 1909, funda el Teatro para los niños en el Teatro Príncipe Alfonso, vinculado también a la renovación escénica española (Pascual 2008: 17). Adriá Gual, por su parte, fue el alma del Teatre Íntim, que también llevó a escena Interior en enero de 1899 en Barcelona (Carbonell Graells 2004: 44).
} 
muchas de las obras que formaron su corpus fueron, o bien propuestas exclusivamente para títeres — en la línea de las del escritor belga-, o bien pensadas para ser hibridadas con actores de carne y hueso (que también podían estar esbozados como simples muñecos de retablo). De esta manera, el teatro de ensueño acercó el teatro de marionetas a la renovación teatral y lo dotó de una nueva vida. Tradicionalmente, este tipo de espectáculo había sido considerado como «ínfimo, callejero, deleznable, tenido a menudo como una especie de subproducto teatral destinado o bien al público infantil o bien a un público adulto escasamente letrado, nada exigente» (Pedrosa 2014: 79). Por norma general, eran las propias compañías las que disponían sus propios teatrillos, fabricaban también sus propios muñecos e iban haciendo incursiones en pueblos y ciudades, durante las fiestas patronales o en las temporadas estivales. Solo en raras ocasiones estas compañías actuaban en teatros destinados a espectáculos y público burgueses. Hemos hallado constancia, por ejemplo, de locales madrileños dedicados al teatro gignol ${ }^{13}$ — que también se había popularizado en toda la península - a principios del siglo XX. No obstante, sus representaciones se hallaban igualmente destinadas a «enarcar de admiración los ojos o de gozo los labios de dos a diez años», como comentaba el cronista Gil Blas respecto de una compañía de estas características ubicada en el Jardín Botánico de Madrid (Blas 1886).

El teatro de títeres se hallaba, por tanto, fuera de los circuitos comerciales burgueses y adultos, como también lo estaban las propuestas más radicales de los autores que se aproximaron al «teatro de ensueño». Lejos, pues, de hallar espacios de representación comerciales se abrieron paso muchas veces en domicilios particulares, donde un selecto público disfrutaba de sus puestas en escena $^{14}$.

Emilia Pardo Bazán y el proyecto de una Serie de RePresentaciones de TEATRO DE MARIONETAS PROMOVIDAS POR ANTONIO DE HOYOS Y VinENT

De esta penetración daría cuenta Emilia Pardo Bazán, quien, en una crónica de «La Vida Contemporánea» de La Ilustración Artística del 11 de enero de

${ }_{13}$ Así La Época, en su sección «Noticias generales» del 2 de junio de 1901, anunciaba: «Parece que se insiste en la idea de construir un teatro Guignol dentro del Parque de Madrid, y según se dice se ha elegido uno de los sitios más hermosos, cerca de la llamada Casa del Pobre» y en el Anuario del comercio, de la industria, de la magistratura y de la administración de 1903 constan en Madrid el Teatro de la Infancia (Guignol), en la Plaza de la Lealtad, y el Teatro Guignol en el número 12 de la calle Atocha.

${ }^{14}$ Gómez Torres reseña también cómo la pieza para títeres de García Lorca La niña que riega la albahaca y el príncipe preguntón se estrenó en el domicilio del poeta el 5 de enero de 1923. 
1904 — es decir, en fechas cercanas a la composición de La muerte de la Quimera. Tragicomedia en dos actos, para marionetas — advertía: «[1]a idea modernista de teatro de marionetas (...) empieza a tomar cuerpo en Madrid». Además, en la misma sección de la revista barcelonesa, años después, recordaba: «me pidieron una obra para un teatro de marionetas y se me ocurrió glosar el mito de la Quimera antigua» (Pardo Bazán 1902). Como ya hemos apuntado, la representación había sido proyectada para ser representada «en casa de un aristócrata escritor» (como indicaba La Época en su publicación de la pieza el 9 de mayo de 1905). Buscando en la prensa de la época y en la escasísima documentación relativa a las tentativas de teatro particular hemos hallado tanto el nombre propio de este escritor como los datos relativos a su proyecto escénico $^{15}$. Así, el 30/12/1903, Monte-Cristo anunciaba en el diario gaditano La moda elegante:

Entre las fiestas que para el mes próximo se preparan, ha de haber una que llame poderosamente la atención, no sólo del mundo aristocrático, sino del mundo literario. El joven escritor D. Antonio de Hoyos, hijo de la marquesa de Hoyos y de Vinent, y cuyo primer libro - una novelita titulada Cuestión de ambiente - dio no poco que hablar a la crítica, ha tenido la feliz idea de organizar, en las habitaciones que ocupa en el piso bajo del hotel de la calle del Marqués del Riscal, unas representaciones de marionnettes, cuyas obras han sido escritas por muy notables literatos.

Valle-Inclán, el ilustrado refundidor de Fuente Ovejuna y autor de preciosos libros, ha escrito una comedia basada en uno de sus cuentos más celebrados, «La reina de Dalicam». Emilia Pardo Bazán, un drama en dos actos que lleva por título La muerte de la quimera, y que, según dicen los que asistieron a su lectura, es sabroso manjar literario para los paladares refinados. Y, por último, Jacinto Benavente ha dado una obrita suya, El criado don Juan, primorosa como todo cuanto brota de su pluma.

La mise en scene del pequeño teatro, que medirá unos dos metros de anchura, está hecha por un joven artista, al que se deben la mayor parte de las decoraciones del Teatro Español. Y los diminutos artistas, cuyos trajes serán una maravilla de lujo y propiedad, hablarán por boca de la condesa de Requena, de Alicia Longoria, de Blanca Pardo Bazán, de Valle-Inclán, de Jacinto Benavente, de Antonio de Hoyos y otros. Como se ve por lo apuntado, la fiesta promete ser un acontecimiento literario y artístico, y no diré mundano porque la concurrencia, no obstante celebrarse el espectáculo en una casa tan elegante como la de la marquesa de Hoyos, será exclusivamente masculina. Apenas si asistirán dos o tres señoras, y en cambio figurará entre los invitados la plana mayor de la literatura y de la política (Monte-Cristo 30/12/1903).

\footnotetext{
15 Nos ha sido de valiosísima ayuda el artículo de Antonio Espejo Trenas «Arte de salón, marionetas y divertimento modernista en Ramón del Valle-Inclán. Noticia de un proyecto escénico pionero de 1903» que habla de la participación de Valle-Inclán en el proyecto escénico y que reproduce también el artículo de Monte-Cristo publicado en $\mathrm{La}$ Moda Elegante que transcribimos.
} 
Antonio de Hoyos y Vinent era entonces un escritor en ciernes cuya primera novela, Cuestión de ambiente, había sido prologada por Emilia Pardo Bazán, amiga personal de su madre, la marquesa de Hoyos y Vinent, y de su tía Gloria Laguna, marquesa de Requena. A pesar de que nunca había cultivado la dramaturgia, el proyecto de teatro de marionetas del joven aristócrata era una apuesta firme por los más prometedores autores y autoras de la renovación escénica española influenciados por el simbolismo escénico ${ }^{16}$. En su proyecto se hallaban Valle-Inclán, quien legaría para el teatro de títeres obras de gran envergadura ${ }^{17}$, y Jacinto Benavente, que incurriría también en el teatro de muñecos a lo largo de su obra dramática ${ }^{18}$. Este último escritor, además, estaba muy vinculado con algunos de los protagonistas del proyecto promovido por Hoyos y Vinent, ya que se hallaba dirigiendo las representaciones de su comedia Al natural en el conocido como Teatro Alicia ${ }^{19}$. Este espacio privado era propiedad de Alicia Longoria y pasaba por ser uno de los más activos teatros particulares de Madrid. Contaba incluso con una «compañía», en la que figu-

16 No es por ello extraño encontrar un extenso artículo de su autoría sobre el teatro de Maeterlinck en La Época el 11/03/1904 cuando el dramaturgo belga visita España.

17 Como señala Villarmea «el interés por el teatro de muñecos como vehículo de representación se remonta a sus comienzos literarios, con una mención de este tipo de espectáculo en su relato "La reina Dalicam", publicado el 20 de abril de 1899 en la revista La vida literaria (...), siendo La cabeza del dragón, escrita y estrenada en 1910, el primer texto relevante de esta modalidad, si atendemos a la clasificación de 1926, que la recoge bajo el título Tablado de marionetas, junto a la Farsa de la enamorada del rey (1914) y Farsa y licencia de la reina castiza (1922). De la misma forma, La rosa de papel y la cabeza del bautista, subtituladas "novelas macabras" en 1924, pasan a ser "Melodramas para marionetas" al integrarse en el Retablo de la avaricia, la locura y la muerte en 1927. Además de las obras que en su título genérico hacen referencia a la marioneta, ciertas declaraciones del escritor en que afirma escribir para marionetas confirman que hacia los años veinte Valle-Inclán asociaba la etiqueta de "esperpento" a "teatro de muñecos"» (2006: 161).

${ }^{18}$ En su Teatro fantástico Jacinto Benavente incluyó la comedia para marionetas $L a$ senda del amor y el argumento para pantomima La blancura de Pierrot. Como señala Peral Vega (2004: 19) «se suma con sus dos piececillas a esta resurrección artística del muñeco. En El encanto de una hora, dos figurillas de porcelana, Merveilleuse e Incroyable, nacen súbitamente a la vida, lo que permite a Benavente, desde el distanciamiento conferido por sus personajes, lanzar su mirada ácida contra lo anodino de la existencia humana, por mucho que al final prevalezca el poder redentor del amor. En La senda del amor ilustra, de acuerdo con el ideario modernista en que se inserta, la exaltación del amor ensoñado y efímero, frente a los tratamientos estereotipados que de la materia sentimental se hacían desde el teatro más convencional».

19 En el apartado «De sociedad» de El Liberal del 23/12/1903 se transcribe: «En la función teatral qua ha de celebrarse en el hotel de los señores de Longoria (D. Javier), se representará la aplaudida comedia Al natural, ha poco estrenada en Lara. Los principales personajes estarán representados por las señoritas de Longoria, las de Quiroga y Pardo Bazán y la condesa de Requena, con otros aristocráticos actores. Al lindo teatro Alicia asistirá, para dirigir los ensayos, el autor de la obra, Jacinto Benavente». 
raban Blanca y Carmen Quiroga, las hijas de Emilia Pardo Bazán. La propia escritora tendría también un especial protagonismo en este teatro particular, ya que muy poco tiempo después, participaría activamente en uno de sus espectáculos ${ }^{20}$. Parece incluso que el Teatro Alicia y la representación promovida por Antonio de Hoyos y Vinent fueron empresas escénicas muy relacionadas. Ambas contaron con los mismos protagonistas, quienes procedían de una élite capitalina que conjugaba a aristócratas, intelectuales y otros miembros de la clase alta que se interesaban por el teatro.

Sin embargo, las proyectadas representaciones de títeres no se llevaron a cabo, aunque desconocemos los motivos. Sí hubo, no obstante, una lectura de La muerte de la Quimera por parte de la propia Pardo Bazán como muestra la referida crónica de La Moda Elegante, que debió de ser muy aplaudida y que repercutió sin duda en la posterior publicación de la obra. Además, durante el proceso de escritura de su tragicomedia de ensueño, Pardo Bazán se vio inmersa en un proceso de documentación y reflexión sobre el teatro de marionetas, descubriendo en él, a la manera de Maeterlinck, un «profundo simbolismo», como desvela en su ya citada crónica del 11 de enero de 1904:

Como nadie ignora, las marionetas son regidas por hilos más o menos invisibles, o por manos fuertes y diestras que las revisten de ilusión y de movimiento espontáneo; y esta disposición de las marionetas da que reflexionar. Acaso a la humanidad, en conjunto, la sucede exactamente lo mismo. Creemos vivir, y nos viven, mejor dicho, nos comunican apariencias de vida esos cordelitos y esos dedos ocultos que agitan nuestros brazos mientras una voz finge salir de nuestra boca y realmente parte de entre bastidores. Si la marioneta pudiese hablar, protestar, ser persona, ¡qué de cosas diría; cómo desmentiría el papel que la obligan a representar mecánicamente! (Pardo Bazán 1904a).

Este texto parece funcionar como una especie de poética de la escritora sobre el teatro de títeres. En él Doña Emilia, explica el efecto de ensueño que provocan sus protagonistas, tras distinguir entre los títeres de hilos y los de guante:

${ }^{20}$ Hablamos concretamente de la La nuit d'Octobre de Alfred de Musset, que sería interpretado por la propia Alicia Longoria y que contó con un juego escénico que había sido ideado por Doña Emilia, como recoge la siguiente crónica titulada «Teatro Alicia. Un ensayo general» y publicada en La Época el 20 de febrero de 1904: «en esta representación ofrece una encantadora novedad. Como nadie ignora, en el diálogo con la Musa, el poeta lanza imprecaciones contra Jorge Sand, que le engañó, y a quien trata de olvidar. En tal momento, en el fondo de la decoración aparécese la figura de Jorge Sand personificada en la hermosa Paquita Longoria. Su traje también es de la época romántica. Al decir el poeta que olvida su desgraciado amor, la figura desaparece. Este efecto escénico es muy hermoso, y lo será más cuando los Sres. de Longoria puedan disponer, en vez del reducido escenario actual, del magnífico teatro que en la calle de Fernando VI están construyendo en su original palacio modernista. Esta aparición ha sido ideada por la ilustre escritora $D^{\mathrm{a}}$ Emilia Pardo Bazán». 


\begin{abstract}
Las marionetas propiamente dichas son las manejadas por hilos; los pupazzi son las figurillas movidas por la mano. Estas se prestan mejor a lo cómico: las primeras, a lo dramático irreal. Su modo de deslizarse por el escenario, sin pisar, tiene mucho de esa suavidad ingrávida que caracteriza a las apariciones. Si un velo transparente se interpone entre el espectador y la marioneta; si los prestigios de la luz eléctrica adoptada a lo escénico las envuelven y las desmaterializan, nos transportan fácilmente a la región de los ensueños. Tal es quizás la causa del prestigio que las marionetas ejercen hoy sobre los inclinados al modernismo. Estamos en una época en que lo demasiado verdadero abruma el alma (Pardo Bazán 1904a).
\end{abstract}

Además, la escritora cuenta la historia de este tipo de muñecos articulables que existen «desde que el hombre pudo sentir pruritos de arte, de queja, de imitación, de exteriorización de la fantasía» y cita a los autores y autoras que se aproximaron a este tipo de género como Jorge Sand, quien poseía un teatrillo privado para sus hijos y «un autor tan refinado como Mauricio Maeterlinck», de cuya obra adivina vinculaciones con Cervantes:

Cervantes — de actualidad ahora - nos ofrece en el Quijote una página de marionetas, en la cual, voluntaria o involuntariamente, hay plétora de simbolismo. Es la del retablo de maese Pedro, y la representación de las aventuras de Gaiferos y Melisendra. Tal vez esta página del Quijote inspiró a Metterlinck (sic) uno de sus poemas dramáticos ${ }^{21}$. Ello es que confundiendo como siempre lo real con lo ideal, toma los títeres por los mismos personajes que representan, y cree que el drama pasa al pie de la letra (Pardo Bazán 1904a).

\title{
El teatro de Maeterlinck en España y Emilia Pardo Bazán
}

En la historia del teatro modernista español hay una fecha, sin duda, muy relevante: el mes de marzo de 1904, que vincula nuevamente a Emilia Pardo Bazán con Maurice Maeterlinck. Durante este mes, y como anunciaron varios medios, tuvo lugar la visita de Maeterlinck a España, acompañado de su pareja, la actriz Georgina Leblanc, quien llevaría a cabo con su compañía las obras del dramaturgo en el madrileño teatro de la Comedia. Su visita generó un gran eco mediático y así, si los diarios, a través de sus críticos teatrales, reseñaron a vuela pluma todas las representaciones que la compañía ofreció; las revistas especializadas en temas literarios se centraron en analizar su obra y su poética teatral, y las revistas se centraron en apuntar los rasgos más sobresalientes de la obra del escritor belga.

Pardo Bazán, que por el entonces gozaba de cierto éxito en los escenarios tras el estreno de su diálogo La suerte —influido también por el escritor-, se

${ }^{21}$ Tal vez, por la paronimia entre los dos nombres de los dos personajes femeninos, se refiera a la obra del escritor belga Pelléas et Mélisande. 
propuso saludar la llegada de la dramaturgia maeterlinckiana a las tablas madrileñas con un nuevo artículo de su serie «La Vida Contemporánea» de La Ilustración Artística el 21 de marzo de 1904:

El teatro de Maeterlinck — a la lectura - no parece de los más representables. Su misma delicadeza y vaguedad tienen poco de arte dramático, según las fórmulas consagradas, que requieren acción y movimiento, unidos a cierta claridad y precisión que permitan al público apoderarse del pensamiento del autor y del asunto de la obra (Pardo Bazán 1904b).

Si bien, reconocía que la posibilidad que tendría el público de ver su teatro representado sería un hecho muy positivo en la difusión de su obra:

Aquí, en España, Maeterlinck, admirado por la nueva generación no es conocido por la mayoría del público, ni su fama ha corrido como la de un Zola, un Sienkiewicz o un Tolstoy. Ni aun se ha repetido su nombre como el de un D'Annunzio. Seguramente si Maeterlinck no tiene la buena idea de servir su literatura en las tablas, con actividad y decisión; si se limita a presentarla en las páginas del libro, hubiese llegado a Madrid pasando inadvertido, como casi pasó inadvertido Brunetiére, y sin casi Mauricio Barrés. Sabríamos su llegada — si es que la sabíamos - los que le hubiésemos leído, interesados por la originalidad de su talento y por el sabor a fruto nuevo de su inmaterial y soñada concepción del mundo y de la vida; pero la multitud, ¿qué hubiese sospechado de Monna Vanna, de Joyzelle, del repertorio que tan nutrido abono lleva al teatro de la Comedia, a no ser por el recurso escénico, el atractivo de curiosidad y de fiesta que reviste la presentación de una compañía extranjera, precedida de la fama y aplaudida al través de Europa? (Pardo Bazán 1904b).

Y tras estas declaraciones, Doña Emilia se detenía, en su crónica, a analizar la filosofía del escritor belga que había trascendido a través de su libro $L a$ sabiduría y el destino y que mostraba un manifiesto tono pesimista y una concepción de la asunción del destino próxima a la manifestada en el propio teatro del escritor.

\section{LA MUERTE DE LA QUimera. TRAGicomedia EN DOS aCtos, PARA MARIONETAS}

Parte de esta concepción maeterlinckiana subyace a La muerte de la Quimera, si bien, esta acusa también el peso del fatum presente en el teatro griego, en el que la escritora debió buscar inspiración para su pieza. De hecho, en fechas cercanas a su redacción — tal vez en el período de su escritura misma-, el 7 de diciembre de 1903, Doña Emilia reflexionaba en una crónica:

La idea de la alegría griega, de la feliz y risueña existencia pagana, es muy discutible ante una crítica que tome en cuenta los textos generales y la misma literatura bella, por ejemplo la dramática. Todo el teatro griego es una serie de inauditos 
crímenes y dolores; la fatalidad se cierne sobre él, envuelta en nubes de sangre; Atreo, Filoctetes, Medea, Jasón, Electra, Orestes, Clitemnestra, Antígona, de todo tendrán menos de alegres y serenos, de risueños y de olímpicos. El peso del destino, de la fatídica ley, gravita sobre ese teatro con más fuerza que sobre ninguna de las obras de arte literario que después vienen. De ninguna lectura surge imponiéndose lo amargo y desconsolador de la vida humana como del teatro griego, y creo que no hay libro místico que así demuestre la nada de las cosas, la vanidad del sueño que soñamos entre la cuna y el sepulcro (Pardo Bazán 1903).

Así, su Tragicomedia en dos actos, para marionetas es un texto que recrea la historia mitológica en la que Belorofonte mata a la Quimera, además de añadir un fabuloso encuentro entre el primer personaje y Casandra, hija del rey Yobates $^{22}$. En palabras de la propia escritora, en este proyecto:

Se me ocurrió glosar el mito de la Quimera antigua. Belerofonte, que viene a luchar con la Quimera, encuentra en el palacio de Yobates a la princesa Casandra. Se enamoran apasionadamente y deciden huir juntos, así que Belerofonte haya dado muerte al monstruo. Minerva, diosa de la Razón, ayuda a Belerofonte en la empresa. Apenas la Quimera sucumbe, el amor loco, el entusiasmo heroico, perecen con ella. Casandra y Belerofonte, antes tan entusiasmados, se apartan sin mirarse: Belerofonte huye del peligro de que le asesinen en el palacio del padre de Casandra, y Casandra de la vida azarosa que la espera si une su suerte a la del príncipe proscrito...

Era el aliento febril del endriago lo que los había unido: al sucumbir la Quimera, disípanse los ensueños, las hermosas locuras... (Pardo Bazán 1912).

La pieza se distribuye en dos actos (el primero de cuatro escenas y el segundo de seis). Antes del texto, la dramatis personae, titulada por Pardo Bazán simplemente «personajes», presenta a los actantes de la tragicomedia y proporciona datos relativos a su edad. Así, señala:

\section{Personajes}

BELEROFONTE, hijo de Glauco, Rey de Corinto 30 años

YOBATES, Rey de Licia 60 años

UN RAPSODA 40 años

U N PASTOR 20 años

LA INFANTA CASANDRA, hija de Yobates 19 años

MINERVA, diosa de la Razón

LA QUIMERA, monstruo. (No habla) (Pardo Bazán 1905).

En la primera escena de la breve pieza, Casandra, hija del rey de Licia, mantiene una conversación con un Rapsoda y en sus palabras, gravita la extrañada

22 En la mitología clásica se llamaba Filónoe o Anticlia (Grimal 1990: 70). 
melancolía de la protagonista de Pélléas et Mélisande de Maurice Maeterlinck: «Estoy enferma de pasión de ánimo. Dicen que soy feliz... nada me falta» (Pardo Bazán 1905). A continuación le relata que tiene el corazón oprimido, a pesar de lo muchos bienes materiales con los que cuenta. El Rapsoda le responde:

Tu estado, Infanta, es igual al de todas las doncellas y los mozos de este Reino desde que vivimos bajo el terror de La Quimera, cuyo aliento de llama engendra la fiebre y el frenesí. El monstruo, a quien nadie se atreve, se habrá aproximado a los jardines de tu palacio, rondando tus establos o buscando quizás presa más noble, y te ha inficionado con ese veneno de melancolía y de aspiraciones insanas. ¿Cuándo un héroe, un nuevo Teseo, nos libertará de la Quimera maldita? (Pardo Bazán 1905).

El héroe no tarda en aparecer: es un extranjero llamado Belerofonte, quien ha conseguido domesticar a Pegaso y que procede de la corte del Rey Preto, casado con Antea, la hermana de de Casandra. Belorofonte le cuenta a esta que es hijo de Glauco, rey de Corinto, y que vaga empujado por «la cólera de los inmortales» y por la mala suerte. Enseguida, Casandra, ensimismada por sus palabras, empatiza con él: «La compasión, como un cuchillo que hiere sin lastimar, me atraviesa las entrañas. Tus males ya son míos. Extranjero, aquí encontrarás asilo y defensa hasta que la mala suerte se canse de perseguirte», le dice. Belorofonte trae una misiva escrita por el Rey Preto para Yobates, rey de Licia y padre de Casandra, pero antes de entregársela a su destinatario cuenta a la joven princesa la historia que lo ha convertido en un héroe: ha conseguido domesticar a Pegaso. También le cuenta que, de camino a Licia, ha visto a La Quimera y que se halla ensimismado con ella: «Cerca del templo de Haifestos he sentido su resuello ardiente en la espalda. Me volví, y nadie había», dice.

En la tercera escena, se une a los dos protagonistas el Rey Yobates, padre de Casandra. Belorofonte le entrega la misiva al monarca, si bien advirtiéndole que deberá leerla a solas. En el diálogo que mantienen los personajes salen a la luz varios hechos sobre el pasado de Belorofonte. Así, él mismo cuenta cómo consiguió vencer a Pegaso, mientras Yobates recuerda la tragedia de Belorofonte al matar, sin querer, a su hermano. Y, en términos que, a la vez recuerdan la concepción de la dramaturgia maeterlinckiana y constituyen una referencia metateatral, declara:

Los dioses, oh Rey, nos tejen la tela del existir; suponemos que caminamos, y es que invisibles manos nos impulsan. En la Acrópolis de Corinto hemos elevado un templo a la Fatalidad. La diosa tiene los brazos de plomo, las manos de bronce, y en una lleva el martillo y en otra los clavos de diamante que fijan nuestro destino. Nuestras culpas involuntarias nos pesan como voluntarias: Edipo, sin delito en la voluntad, vagó ciego y perseguido por las furias; yo vago expatriado y $\sin$ familia (Pardo Bazán 1905).

Belorofonte deja a solas al rey Yobates y a Casandra, quienes leen la misiva que este traía del rey Preto. Pero en esta carta, sorpresivamente, el monarca 
pide a Yobates que acabe con la vida de Belerofonte, ya que ha deshonrado a Altea, mujer de Preto e hija de Yobates. Este último, entonces, idea un plan: pide al héroe que acabe con la Quimera para no tener que matarlo. Como tratándose de un cuento tradicional, Belorofonte pide la mano de Casandra si consigue acabar con el monstruo.

En el segundo acto, Casandra y Belerofonte se citan ante una estatua de Eros, ante la que mantienen un diálogo amoroso. Allí, la joven cuenta, asustada, el contenido de la carta de Preto, y pide a Belorofonte que huya. Este confiesa que su relación con Antea fue cierta, si bien aclarándole a Casandra:

Te amé en ella antes de amarte en ti misma. Es tan hermosa como tú, pero tú, piadosa virgen, por dentro eres blanca como el vellón de las ovejas de tu aprisco; a ti, no a ella, aspiraba mi espíritu, ansioso de algo muy grande. La propuse que siguiese mi errante destino y rehusó: no quería dejar el palacio donde es reina, el lecho de marfil, las ricas estancias con artesonados de cedro. No me quería (Pardo Bazán 1905).

Y la joven, sin dudarlo, le responde: «Yo iré adonde tú vayas, y pisaré tu huella con los pies descalzos. Si esposa, esposa; si amante, amante; si esclava, esclava». Pero antes de huir con ella Belerofonte le manifiesta su decisión de acabar con La Quimera, empresa que estremece su «corazón de gozo y de locura». Casandra, quien también reconoce su atracción por este ser — «siento igualmente una especie de atracción extraña por el monstruo. Quisiera conocer su aspecto terrible», le confiesa - acepta. Pasan la noche juntos y por la mañana, Casandra se esconde cerca de la cueva de la Quimera para ver el combate entre su amado y el monstruo. De repente, aparece en escena la diosa Minerva, protectora de Belorofonte.

La diosa anima al héroe en su empresa: «Alienta, hijo de Glauco, domador del corcel divino. Libra a la tierra de ese endriago que trastorna las cabezas y me impide hacer la dicha de la humanidad, apagando su imaginación, curando su locura y afirmando su razón, siempre vacilante». A continuación, pronostica: «Muerta la Quimera, empieza mi reinado». Acto seguido, la diosa le aconseja al hijo de Glauco que introduzca su espada en la boca del monstruo para acabar con él. El combate se libra finalmente y Belerofonte, siguiendo el consejo de Minerva, acaba con el monstruo.

Hasta este punto y si bien con algunos cambios ${ }^{23}$, Pardo Bazán es rigurosa con el seguimiento de la leyenda entre Belerofonte y la Quimera que, según Pierre Grimal (1990: 70-71), fue recogida por Hesíodo, Píndaro, e Higinio. Sin embargo, en la obra de todos estos autores, una vez muerto el monstruo, Yobates invita a Belerefonte a quedarse con él y ofrece en matrimonio a su hija. Sin embargo, en la tragicomedia para marionetas de Pardo Bazán, ocurre algo muy

${ }^{23}$ En la leyenda es Atenea y no Minerva la protectora de Belorofonte y este es falsamente acusado de forzar a Antea, quien lo incrimina al negarse a tener relaciones con él. 
diferente. Con la muerte de la Quimera se acaba su poder y se desvanece tanto la influencia que ejercía sobre los personajes como todo el tono de irrealidad de la obra. Es decir, se acaba el ensueño. Los personajes parecen despertar y así, tras acabar con el monstruo Belerofonte se pregunta al comienzo de la escena sexta: «¿Por qué he luchado con ella? ¿Por qué la he matado? He corrido un riesgo espantoso, inaudito. ¿Quién me ha metido a mí en tal empresa?». Al tiempo, huye tras recordar que Yobates tiene orden de asesinarlo. Mientras, Casandra, por su parte, no parece recordar nada y cambia su tono de ensimismamiento para mostrarse caprichosa y pizpireta: «¿Por qué estoy aquí? ¿Cómo se me ha ocurrido dejar mi palacio magnífico, mi lecho de marfil cubierto de tapices de plumón de cisne? Ahora tengo frío, y las asperezas de la sierra me han lastimado las plantas. ¡Cómo me duelen!». Finalmente, declara resuelta:

Ea, yo regreso a mis jardines. Allí me lavarán los pies y me servirán leche y frutas. Me siento desfallecida de hambre. ¿Estaría loca, para no mandar que me esperase ahí cerca el carro, cuyos caballos enjaezados de púrpura me trasladan de una parte a otra tan velozmente? En fin, no habrá más remedio que andar a pie. ¡Es divertido! (Pardo Bazán 1905).

Los dos personajes se marchan, cada uno por su lado, sin ni siquiera mirarse. Liberados del ensueño y de la melancolía producidos por el monstruo - casi parece que se han desprendido también de sus cuerdas de marioneta-, vuelven otra vez a un mundo ordenado en el que no recuerdan su amor apasionado. Por último, como colofón final, la diosa Minerva, sola en la escena declara: «¡Gloria al héroe! ¡La Quimera ha muerto!». Como pronosticaba, ha empezado su reinado, el reinado de la razón.

Así, y como había adelantado la propia escritora, la pieza de ensueño de Pardo Bazán encierra dentro de sí otra pieza de ensueño: la que la Quimera produce sobre los otros personajes y se rompe cuando el monstruo es asesinado. Como la propia escritora define «Era el aliento febril del endriago lo que los había unido: al sucumbir la Quimera, disípanse los ensueños, las hermosas locuras...» (Pardo Bazán 1912).

Desafortunadamente, y como hemos dicho, esta pieza no ha tenido la relevancia adecuada. El frustrado proyecto de su representación de marionetas y el hecho de prologar la novela de 1905 La Quimera han rendido el texto a un olvido crítico injustificado. Sin embargo, nos parece fundamental releer $L a$ muerte de la Quimera para reubicarla dentro del corpus de obras del «teatro de ensueño y de títeres», llamados a renovar la dramaturgia hispánica, así como resituar el teatro de Emilia Pardo Bazán en el primer eslabón de la renovación dramática del siglo $\mathrm{XX}^{24}$.

24 Asimismo, también la relectura de parte de su obra a la luz de la influencia de Maurice Maeterlinck, ofrece nuevas claves interpretativas sobre las que examinar no solo algunos 


\section{BIBLIOGRAFÍA CITADA}

Anónimo (1899). «Teatro Artístico», La Correspondecia de España. 1 de enero.

Ayuso, Adolfo y Helena Millán (2001). Historia y mecánica de la marioneta en España. Zaragoza: Diputación de Zaragoza.

Blas, Gil (1886). «Crónica de la semana», Diario oficial de avisos. 3 de julio.

Bobes Naves, Carmen (1991). Semiología de la obra dramática. Madrid: Taurus Humanidades.

Carballal Miñán, Patricia (2006). «La Edad Media en los cuentos de Emilia Pardo Bazán», en José Manuel González Herrán, Cristina Patiño Eirín y Ermitas Penas Varela (coords). Emilia Pardo Bazán: los cuentos. II Simposio Emilia Pardo Bazán. A Coruña: Real Academia Galega, pp. 271-279.

Carbonell Graells, Elena (2004). Els drames «per marionetes» de Maurice Maeterlinck a la Barcelona del tombant de segle. Trabajo de fin de máster inédito. Barcelona: Universitat Autònoma de Barcelona. Accesible en: <https://www.academia.edu/Messages/956839>.

Espejo Trenas, Antonio (2012). «Arte de salón, marionetas y divertimento modernista en Ramón del Valle-Inclán. Noticia de un proyecto escénico pionero de 1903», en Margarita Santos Zas, Javier Serrano Alonso y Amparo de Juan Bolufer (coords.), Valle-Inclán y las artes. Santiago de Compostela: Universidade de Santiago de Compostela, Servizo de Publicacións e Intercambio Científico, pp. 277-288.

González, Salvador (2000). «Introducción», en Maurice Maeterlinck, La intrusa. Los ciegos. Pelléas y melisande. El pájaro azul. Madrid: Cátedra.

Gómez Torres, Ana María (1994). «La carnavalización en el teatro: los títeres y la ruptura del canon dramático», Analecta malacitana: Revista de la Sección de Filología de la Facultad de Filosofía y Letras. 17 (2), pp. 313-322.

Grimal, Pierre (1990). Diccionario de mitología griega y romana. Barcelona: Paidós.

Lavaud, Jean-Marie y Eliane Lavaud (1992). «Valle-Inclán y las marionetas entre la tradición y la vanguardia», en Dru Dougherty y María Francisca Vilches de Frutos (coords.), El teatro en España: entre la tradición y la vanguardia 1918-1939. Madrid: Consejo Superior de Investigaciones Científicas-Fundación Federico García Lorca, pp. 361-374.

Monte-Cristo (1903). «De casa y de fuera», La Moda Elegante. 30 de diciembre.

Pardo Bazán, Emilia (1999). Obras completas V (Novelas). La Quimera, La Sirena Negra, Dulce Dueño. Madrid: Biblioteca Castro.

Pardo Bazán, Emilia (1903). «La Vida Contemporánea», La Ilustración Artística. 7 de diciembre.

de sus textos teatrales, sino también varias piezas de su narrativa. Al margen de la novela La Quimera, muchos de sus cuentos acusan la recepción del simbolismo - acaso maeterlinckiano-, y presentan similitudes notables con La muerte de la Quimera. Así, por ejemplo, Quesada Novás (2006: 67) señalaba cómo en los relatos "Cuento soñado» y «Presa» era «la presentación de lo más verosímil» la que acababa con la idealidad con la que eran presentadas sus protagonistas y en nuestro breve estudio «La Edad Media en los cuentos de Emilia Pardo Bazán» (Carballal Miñán 2006: 274-277) indicábamos también la desaparición del «idealismo intimista» de algunos personajes mediante la irrupción de circunstancias más realistas, como sucede en el «El panorama de la princesa» o incluso en «La leyenda de la torre» - relato en el que la irrupción del positivismo se contrapone a leyenda de su protagonista- . No obstante, la recepción del simbolismo del escritor belga en la narrativa de Pardo Bazán excede los límites de este artículo. 
Pardo Bazán, Emilia (1904a). «La Vida Contemporánea», La Ilustración Artística. 11 de enero.

Pardo Bazán, Emilia (1904b). «La Vida Contemporánea», La Ilustración Artística. 21 de marzo.

Pardo Bazán, Emilia (1905). «La muerte de La Quimera. Tragicomedia en dos actos, para marionetas», La Época. 5 de mayo.

Pardo Bazán, Emilia (1912). «La Vida Contemporánea», La Ilustración Artística. 13 de mayo.

Pardo Bazán, Emilia (2016). Perder y salir ganando. Comedia en tres jornadas y en verso, edición, estudio y notas de Dolores Thion Soriano-Mollá. Santander: Sociedad Menéndez Pelayo.

Pascual, Itziar (ed. lit.) (2008). Teatro español para la infancia y la juventud (1800-1936). Madrid: Fundamentos.

Patiño Eirín, Cristina (1994-1995). «La Quimera, de Emilia Pardo Bazán en dos ediciones recientes», Archivum. Revista de la Facultad de Filología. 44-45 (2), pp. 29-42.

Pedrosa, José Manuel (2014). «El Teatro de Títeres: entre el Abismo Poético y el pesimismo Filosófico», Liburna. 7, pp. 79-98.

Peral Vega, Emilio Javier (2004). «El teatro breve de Jacinto Benavente», Cuadernos para investigación de la literatura hispánica. 29, pp. 17-38.

Quesada Novás, Ángeles (2006). «Los cuentos de Emilia Pardo Bazán en el aula», en José Manuel González Herrán, Cristina Patiño Eirín y Ermitas Penas Varela (coords), Emilia Pardo Bazán: los cuentos. II Simposio Emilia Pardo Bazán. A Coruña: Real Academia Galega, pp. 59-88.

Rubio Jiménez, Jesús (1993). El teatro poético en España. Del modernismo a las vanguardias. Murcia: Publicaciones de la Universidad de Murcia.

Sánchez Llama, Ínigo (2005). «El mito de la Quimera como tropo genérico de la modernidad en Emilia Pardo Bazán», Revista de estudios hispánicos. 39 (3), pp. 439-463.

Varey John E. (1956). Historia de los títeres en España desde sus orígenes hasta el siglo XVII. Madrid: Revista de Occidente.

Vázquez de Castro, Isabel (2001). Le théâtre de marionnettes populaires et son influence sur le renouveau scènique au cours du vingtième siècle en Espagne. Villeneuve d'Ascq: Les Presses Universitaires du Septentrion.

Villarmea Álvarez, Cristina (2006). «Teatros de marionetas: la influencia de Valle-Inclán en El Señor Presidente de Miguel Ángel Asturias», Moenia: Revista lucense de lingüística \& literatura. 12, pp. 157-169.

Whitaker, Daniel S. (1988). La Quimera de Emilia Pardo Bazán y la literatura finisecular. Madrid: Editorial Pliegos.

Yxart, José (1894). «Lecturas. El arte escénico en España», La Época. 14 de agosto.

Fecha de recepción: 26 de julio de 2016.

Fecha de aceptación: 26 de enero de 2017. 